\title{
Therapeutics targeting the main protease of SARS- CoV-2 for the treatment of COVID-19: A molecular modeling approach deciphering relative efficacies
}

Shuvasish Choudhury

Assam University, Silchar, India

Purbajyoti Saikia

Dhemaji College, Assam, India

Debojyoti Moulick

Assam University, Sllchar, India

Muhammed Khairujjaman Mazumder ( $\sim$ khairujjaman1987@gmail.com )

Dhemaji College, Dhemaji, Assam, India

\section{Research Article}

Keywords: Coronavirus, Main protease, Molecular docking, Plant derived natural products,

Phytochemicals, 2019-nCoV

Posted Date: November 18th, 2020

DOI: https://doi.org/10.21203/rs.3.rs-110749/v1

License: (a) This work is licensed under a Creative Commons Attribution 4.0 International License.

Read Full License 


\section{Abstract}

The pandemic due to the novel coronavirus 2019, SARS-CoV-2, has led to a global health and economic crisis. The disease, named coronavirus disease (COVID-19), has already affected 3090445 and killed over 217769 people worldwide, as of April 30,2020. So far, there is no specific effective medicine or vaccine against SARS-CoV-2. Several existing and approved drugs are under clinical studies for re-purposing. However, owing to the emergent situation and thereby to avoid time needed for de novo drug discovery, drug re-purposing remains to be the best option to find an effective therapeutic against the virus. Thus, the preset study was designed to evaluate potency of 82 compound/drugs in inhibiting the main protease (3CLPro) of SARS-CoV-2, using molecular docking tool. This protease is a vital enzyme for replication of the virus, and is thus a promising drug target. The analyzed compounds include 16 known protease inhibitors, two recently suggested a-ketoamides, 24 recently reported putative inhibitors, and 40 phytochemicals. The results indicate that Ritonavir, Indinavir, Montelukast, Nelfinavir, Candoxatril, Tigecycline and Lopinavir to be very potent protease inhibitors. Further, several other drugs and compounds, including phytochemicals, have been identified / predicted to be potent in inhibiting the enzyme. In addition, we hereby report relative efficacies of these compounds in inhibiting 3CLPro. Thus, the present study is significant in the therapeutic intervention of COVID-19.

\section{Introduction}

There have been three major outbreaks of severe acute respiratory syndrome (SARS) caused by coronaviruses (CoVs) in the current century. First, the SARS caused by SARS-CoV in 2002-03; second, the Middle East Respiratory syndrome (MERS) caused by MERS-CoV in 2012; and now a novel CoV emerged from Wuhan, China in December 2019 [1]. This novel CoV was initially named 2019-nCoV, and was subsequently re-named SARS-CoV-2 by viral taxonomists, owing to its similarity with the SARS-CoV. The World Health Organization (WHO) has named the disease coronavirus disease (COVID-19), the symptoms of which include cough, sneezing, dyspnea, fever, shortness of breath, pneumonia and in severe cases multi-organ failure occurs [2-4]. Initially, WHO declared the outbreak as Public Health Emergency of International Concern on 30 January, 2020. Subsequently, it was declared a pandemic on 11 March, 2020. The virus has already spread to more than 216 countries/area/territories across the globe, and affected 4761559 and killed over 317529 people, as of $20^{\text {th }}$ May, 2020 (https://www.who.int/emergencies/diseases/novel-coronavirus-2019). The global humanity is currently in a grave crisis due to the pandemic, which has already caused great loss of life and property, and affected global economy severely.

SARS-CoV-2 is an enveloped virus containing plus-sensed single-stranded RNA genome. Since the virus shares $88 \%$ sequence identity with CoVs of bat and $50 \%$ identity with MERS-CoV [5], it is though that the virus has a zoonotic origin from bats. While the medical professionals are over-burdened by the increasing number of new cases and paucity of infrastructures, research community is eagerly searching 
for therapeutic interventions. Since developing novel therapeutic agents against any pathogen is a timeconsuming venture, and looking at the burgeoning crisis, one of the best strategies is re-purposing of existing drugs as a strategy to shorten time and reduce cost which occur in de novo drug discovery [6-7]. Thus, the search for potential therapeutics which can potentially inhibit replication of the virus continues [8].

Structural biology approaches, including crystallography, electron microscopy and homology modeling, have determined and revealed three-dimensional structures of several drug targets of SARS-CoV-2, including main protease (3-chymotrypsin-like protease; 3CLpro), papain-like protease, endoribonuclease, ADP ribose phosphatase, spike protein, nucleocapsid protein, RNA-dependent RNA polymerase (RdRp), etc. Li and De Clercq [9] suggested 3CLpro, papain-like protease, helicase, and RdRp and spike glycoprotein to be the five targets against the virus. So far, remdesivir, an antiviral drug targeting RdRp, has been suggested for use in COVID-19 patients [10]. Also, hydroxychloroquine in combination with remdesivir has been reported to be highly effective against SARS-CoV-2 in vitro [10-11]. Gao et al. [12] reported from clinical studies that chloroquine phosphate has efficacy in treating COVID-19 associated pneumonia. Further, nucleoside analogues, which are RdRp inhibitors, including favipiravir, ribavirin and galidesivir have been suggested for use in COVID-19. These are reported to be effective against several related viruses including influenza, Ebola, yellow fever, chikungunya, norovirus and enterovirus, and even SARS-CoV-2 $[9,10,13]$.

Zhang et al. [14] have suggested a-ketoamide derivatives for inhibiting the main protease. Using molecular modeling approaches, Wu et al. [15] have suggested a large number of compounds which can inhibit different drug targets of the virus. Their list includes known compounds as well as natural products against 3-CLpro, Spike, RdRp and papain-like protease. The present study endeavors to identify compounds which can potentially inhibit the main protease of SARS-CoV-2, 3CLpro, using molecular docking approaches. 3CLpro is essential for processing the polyproteins that are translated from the positive-sensed viral RNA genome upon infection of host cell, and is thus one of the most important drug targets against SARS-CoV-2 $[14,16]$. We selected 42 compounds which are known to be inhibitors of viral proteases, or which have been reported by others to have the potential to inhibit the enzyme. Further, we have used 40 plant derived natural products to test their efficacy in inhibiting the enzyme. The purpose of this study was to evaluate the relative efficacy or potential of different known/potential protease inhibitors, as well as determine the potential of some of phytochemicals in inhibiting the 3CLPro.

\section{Methodology}

\subsection{The Drug target:}

The three-dimensional structure of the SARS-CoV-2 main protease (3CLpro) was downloaded from the RCSB Protein data bank. The structure, bearing PDB id 6Y2F, is a crystal structure (monoclinic form) of the complex resulting from the reaction between SARS-CoV-2 (2019-nCoV) main protease and tert-butyl (1-((S)-1-(((S)-4-(benzylamino)-3,4-dioxo-1-((S)-2-oxopyrrolidin-3-yl)butan-2-yl)amino)-3-cyclopropyl-1- 
oxopropan-2-yl)-2-oxo-1,2-dihydropyridin-3-yl)carbamate (alpha-ketoamide 13b). It was expressed in $E$. coli, determined using X-ray diffraction at resolution of $1.95 \AA$, R-Value Free of 0.219 and R-Value Work of 0.178 (https://www.rcsb.org/structure/6y2f). It was deposited in PDB on 2020-02-15 by Zhang et al. [14].

\subsection{The Ligands:}

Sixteen known protease inhibitors were included in the study to determine their relative inhibitory potential, and 24 compounds suggested by Wu et al. [15] from ZINC database, two a-ketoamide inhibitors suggested by Zhang et al. [14] and forty phytochemicals from our in-house database were included in the study (Table 1). Three-dimensional structures of all the compounds were downloaded from the NCBI PubChem compounds database, and their physico-chemical properties including molecular weight, numbers of hydrogen bond donor and acceptor groups, octanol/water oartition coefficient (LogP) and topological polar surface area (TPSA), were recorded (www.pubchem.ncbi.nlm.nih.gov/). For the two ketoamides, the structures were drawn in Mobyle@RPBS (https://mobyle.rpbs.univ-paris-diderot.fr/) to determine the physicochemical properties. For the ketoamides, and ritonavir, lopinavir, saquinavir and indinavir the three-dimensional structures were not available at NCBI database, and were thus drawn and converted, followed by energy minimization.

\subsection{Molecular docking:}

Molecular docking was performed using Molegro Virtual Docker 6.0 software, following standard procedures [17]. Briefly, the structure of the enzyme/receptor was loaded into the workspace, all water molecules were removed, and amino acids with invalid protonation were corrected. Following this, the ligands were loaded and docking was performed between the ligands and active site of the receptor. The bound co-crystallized ligand 06K_502[A], ketoamide, was selected as the reference for docking site (coordinates X: 10.93; Y: -0.46; Z: 20.84) and amino acids with $15 \AA$ were included in the docking. MolDock scoring function was selected with Grid resolution of $0.30 \AA, 10$ runs for each ligand, and 1500 iterations, following Mazumder et al. [18] and Mazumder and Choudhury [19]. The best poses of each ligand, in terms of Rerank score, were selected for further analysis. Limonene, although a plant-derived compound, has no hydrogen bond donor or acceptor group, and was included in the study for validation of the modeling.

\section{Results}

\subsection{Inhibition of the 3CLpro:}

The molecular modeling approach was validated owing to the fact that the co-crystallized ligand (Fig. 1A) and the same ligand when docked (Fig. 1B) have the same docking pose and site of binding. Further, the compound Limonene (which has no hydrogen bond forming group) shows zero hydrogen bond score (Table 1), which further validates the modeling. The molecular docking revealed that the compounds studied have the potential to interact with the active site of the protease. All the compounds bind to the target at the same active site as that of the bound ketoamide (Fig. 1). 


\subsection{Relative potential of the inhibitors:}

One of the mottos of the present study was to identify compounds with high potency in inhibiting 3CLpro. Taking the docking score (Rerank score) as the criterion and indicator of better inhibition of the drug target, the analysis was performed. The docking scores signify the amount of energy liberated when a ligand binds with the active site of a receptor/enzyme [20-22]. Higher, i.e. more negative the docking score stronger is the interaction between the two, and hence more is the inhibitory potential of the compound. The results of the present study indicate that Ritonavir is the best inhibitor with MolDock score of -191.681, Rerank score of -145.68 and hydrogen bond score of -7.6833 (Table 1). Taking the ketoamide [14] as reference, the Rerank score (inhibitory potential) of Ritonavir, Indinavir, Montelukast, Acteoside, Nelfinavir, Rutin, Candoxatril, Tigecycline, Lopinavir and Almitrine were found to be higher by 1.295-, 1.173-, 1.158-, 1.126-, 1.1-, 1.088-, 1.062-, 1.057-, 1.044- and 1.026-fold respectively. Among all these 10 compounds, while Lopinavir had lowest hydrogen bind score (a positive value), while Acteoside showed highest hydrogen bond score of -16.9199 (Table 1). Hydrogen bond score is essentially dependent on the number of hydrogen bond donor and acceptor groups in a compound [17,18], and thus Acteoside with a large number of such groups showed highest Hydrogen bond score.

Among the compounds suggested by Wu et al. [15], Montelukast was found to be the best inhibitor, and Candoxatril, Tigecycline and Almitrine were also highly potent inhibitors of the enzyme. Among phytochemicals, while Acteoside was found to be the best inhibitor of the enzyme, Rutin is also a highly potent inhibitor. All these compounds have inhibitory potentials better than the ketoamides suggested by Zhang et al. [14]. Nevertheless, the docking score of ketoamide 14b ranks eleventh.

\section{Discussion}

Computational molecular modeling approaches, including Molecular docking, are amongst the most vital tools in identifying novel therapeutics against known drug targets. Use of such approaches is highly valuable in the present global crisis due to COVID-19 pandemic, where the research community is meticulously searching for therapeutics against SARS-CoV-2. While the three-dimensional crystal structures of different drug targets have been made available, studies performed on other related CoVs have been of great significance in understanding the replication of this novel virus. Computational studies are being performed to identify known compounds which may potentially interact with and inhibit these targets so as to prevent replication of the virus in human cells.

In our study, we have used 16 known viral protease inhibitors, two ketoamides as suggested by Zhang et al. [14], 24 compounds suggested by Wu et al. [15], and 40 plant-based compounds, and determined their potency in interacting with the active site of 3CLPro of SARS-CoV-2. The docking score, Rerank score, has been considered as a parameter to determine the relative efficacy of the compounds in inhibiting the target. Ritonavir was found to be the best inhibitor of the enzyme, followed by Indinavir. Lopinavir and Nelfinavir. Lopinavir was suggested as a therapeutic option against SARS-CoV-2 by Khan et al. [23], since the compound was found to be effective against others CoVs including MERS-CoV and SARS-CoV [24]. A 
combination of Ritonavir and Lopinavir is has been approved by the FDA for treatment of HIV-1 [25], and were used against SARS $[26,27]$ and MERS $[28,29]$. It was earlier suggested for COVID-19 as well [10]. While Ritonavir is a viral protease inhibitor, it also inhibits the host cytochrome P450 enzyme which metabolizes lopinavir [30]. Thus a combination of the two drugs is given his to enhance bioavailability of Iopinavir [31]. Lopinavir has also been found to be effective against SARS-CoV and MERS-CoV [27,32]. Choy et al. [33] reported antiviral potential of lopinavir against SARS-CoV-2 in vitro. Cao et al. [34] reported from randomized, controlled, open-label trial with 199 COVID-19 positive patients, 99 of whom received Lopinavir/Ritonavir therapy, that the treatment did not improve mortality or detectable viral RNA at different time points. However, in their modified intent-to-treat analysis, there was a reduction in the median time of clinical improvement by 1 day. Nevertheless, although gastro-intestinal adverse events were more common in the treatment group (which may be attributed to side effects of the treatment), severe gastro-intestinal complications were more common in patients not given the antiviral treatment. Further, there was some evidence that the treatment reduced mortality rate as well as shortened ICU stays. Yan et al. [35] performed a retrospective study with 120 hospitalized patients, and reported that the patients who started the therapy within 10 days of onset of the COVID-19 symptoms had a shorter duration of virus shedding, and thus recommended that the therapy should be initiated within 10 days of symptom onset. Thus, it is recommended that large scale clinical trials are conducted using these 3CLPro inhibitors alone or in combination.

Among the compounds suggested by Wu et al. [15], Montelukast was found to be the best inhibitor, and Candoxatril, Tigecycline and Almitrine were also highly potent inhibitors of the enzyme. This is further supported by the findings of Wu et al. [15]. Montelukast is used in the treatment of asthma, whereby the drug reduces bronchial constriction by preventing inflammation [36]. Thus, the drug may reduce respiratory distress in COVID-19 patients as well. Among phytochemicals, while Acteoside was found to be the best inhibitor of the enzyme, Rutin was also a highly potent inhibitor. All these compounds have inhibitory potentials better than the ketoamides suggested by Zhang et al. [14]. Acteoside is a well-known antioxidant, anti-inflammatory, hepatoprotective, cell and immune-regulatory properties [37]. Rutin is a low molecular weight polyphenol, and has several pharmacological activities including antibacterial, antiinflammatory, antiallergic, antiviral, cytoprotective and antihypertensive [38-39]. Among plant secondary metabolites, Acteoside and Rutin were found to be the best inhibitors of the enzyme, and thus may investigated as potential lead molecules against the virus.

Thus, the present study identifies the existing protease inhibitors as antivirals against SARS-CoV-2. These drugs may therefore be tried for clinical studies against COVID-19. Nevertheless, while clinical trials with different antivirals are ongoing, we have identified several plant-based natural products as potent inhibitors of the $3 \mathrm{CLp}$ ro, which may emerge as future therapeutics. The benefit of using such natural products is that most of these are very potent antioxidants and anti-inflammatory compounds. Since COVID-19 is associated with extreme rise in the levels of cytokines including IL2, IL7, IL10, GCSF, IP10, MCP1, MIP1A, and TNFa [40], use of anti-inflammatory drugs remains to be one of the most important strategy in preventing injury to organs [41-44]. Thus, natural products with known anti-inflammatory properties would be highly beneficial in protecting the organs and fatalities in COVID-19 patients. In a 
case study, Ni et al. [45] reported use of traditional Chinese medicine along with Western medicine for the effective treatment of COVID-19. Likewise the plant-based compounds may be used for better management of the disease, which may confer dual benefit. However, this will require in vitro and in vivo studies to ascertain their efficacies.

\section{Conclusion}

In the present global crisis of the COVID-19 pandemic, the world awaits therapeutics against the novel coronavirus, SARS-CoV-2. However, owing to the emergent situation and thereby to shorten time, drug repurposing remains to be the best option to find an effective therapeutic. In this juncture, computational modeling, using molecular docking, is one of the best tools in hand. In the present study, 82 compounds/drugs were tested for their potential in inhibiting the main protease of SARS-CoV-2. Among all the compounds studied, antiviral drugs including Ritonavir, Indinavir, Nelfinavir and Lopinavir were found to be potent in inhibiting the 3CLPro. Other potent 3CLPro inhibiting drugs / compounds include Montelukast, Acteoside, Rutin, Candoxatril, Tigecycline and Almitrine. It is therefore suggested that large scale clinical studies are initiated using the drugs. Further, the secondary metabolites, including Acteoside and Rutin, may serve as lead molecules for development of future therapeutics. Thus, the present study is of immense importance in the therapeutic intervention of COVID-19.

\section{Declarations}

Conflict of interest: None declared.

Funding: The present study has not been funded by any organization.

Ethical disclosure: The present study is a molecular modeling work, and thus does not require ethical approval from any agency.

\section{References}

[1] Song F, Shi N, Shan F, et al. Emerging coronavirus 2019-nCoV pneumonia. Radiology 2020; 200274. DOI: 10.1148/radiol.2020200274.

[2] Zou L, Ruan F, Huang M, et al. SARS-CoV-2 viral load in upper respiratory specimens of infected patients. N Engl J Med. 2020. DOI: 10.1056/NEJMc2001737.

[3] Zou X, Chen K, Zou J, et al. Single-cell RNA-seq data analysis on the receptor ACE2 expression reveals the potential risk of different human organs vulnerable to 2019-nCoV infection. Front. Med. 2020. DOI: 10.1007/s11684-020-0754-0.

[4] Zhu N, Zhang D, Wang W, et al. A novel coronavirus from patients with pneumonia in China, 2019. N Engl J Med. 2020; 382(8): 727-733. 
[5] Lu R, Zhao X, Li J, et al. Genome characterization and epidemiology of 2019 novel coronavirus: implications for virus origins and receptor binding. Lancet 2020. DOI: 10.1016/S0140-6736(20)30251-8.

[6] Cheng F. In silico oncology drug repositioning and polypharmacology. Methods Mol. Biol. 2019; 1878: $243-261$.

[7] Zhou Y, Hou Y, Shen J, et al. Network-based drug repurposing for novel coronavirus 2019nCoV/SARS-CoV-2. Cell Discovery 2020; 6: 14.

[8] Guo D. Old Weapon for New Enemy: Drug Repurposing for Treatment of Newly Emerging Viral Diseases. Virologica Sinica 2020. DOI: 10.1007/s12250-020-00204-7.

[9] Li G, De Clercq E. Therapeutic options for the 2019 novel coronavirus (2019-nCoV). Nature reviews: Drug Discovery 2020; 19: 149-150.

[10] Wang Y, Zhu LQ. Pharmaceutical care recommendations for antiviral treatments in children with coronavirus disease 2019. World Journal of Pediatrics 2020. DOI: 10.1007/s12519-020-00353-5.

[11] Wang $M$, Cao R, Zhang $L$, et al. Remdesivir and chloroquine effectively inhibit the recently emerged novel coronavirus (2019-nCoV) in vitro. Cell Res 2020; 2019-2021.

[12] Gao J, Tian Z, Yang X. Breakthrough: Chloroquine phosphate has shown apparent efficacy in treatment of COVID-19 associated pneumonia in clinical studies. BioScience Trends 2020; 14(1): 72-73.

[13] De Clercq E. New nucleoside analogues for the treatment of hemorrhagic fever virus infections. Chem. Asian J. 2019; 14: 3962-3968.

[14] Zhang L, Lin D, Sun X, et al. Crystal structure of SARS-CoV-2 main protease provides a basis for design of improved a-ketoamide inhibitors. Science, 2020. DOI: 10.1126/science.abb3405.

[15] Wu C, Liu Y, Yang Y, et al. Analysis of therapeutic targets for SARS-CoV-2 and discovery of potential drugs by computational methods. Acta Pharmaceutica Sinica B 2020. https://doi.org/10.1016/j.apsb.2020.02.008.

[16] Hilgenfeld R. From SARS to MERS: Crystallographic studies on coronaviral proteases enable antiviral drug design. FEBS J 2014; 281: 4085-4096.

[17] Mazumder MK, Borah A, Choudhury S. Inhibitory potential of plant secondary metabolites on antiParkinsonian drug targets: Relevance to pathophysiology, and motor and non-motor behavioural abnormalities. Medical Hypotheses 2020; 137: 109544.

[18] Mazumder MK, Choudhury S, Borah A. An in silico investigation on the inhibitory potential of the constituents of Pomegranate juice on antioxidant defense mechanism: relevance to neurodegenerative diseases. IBRO Rep 2019; 6: 153-159. 
[19] Mazumder MK, Choudhury S. Tea polyphenols as multi-target therapeutics for Alzheimer's disease: an in silico study. Med Hypotheses 2019; 125: 94-99.

[20] Mazumder MK, Paul R, Borah A. $\beta$-phenethylamine - a phenylalanine derivate in brain Contributes to Oxidative Stress by Inhibiting Mitochondrial Complexes and DT-Diaphorase: An In Silico Study. CNS Neurosci Therap. 2013; 19(8): 596-602.

[21] Mazumder MK, Bhattacharya P, Borah A. Inhibition of matrix metalloproteinase-2 and 9 by Piroxicam confer neuroprotection in cerebral ischemia: an in silico evaluation of the hypothesis. Med Hypotheses 2014; 83: 697-701.

[22] Mazumder MK, Borah A. Piroxicam inhibits NMDA receptor-mediated excitotoxicity through allosteric inhibition of the GluN2B subunit: an in silico study elucidating a novel mechanism of action of the drug. Med Hypotheses 2014; 83: 740-746.

[23] Khan S, Siddique R, Shereen MA, et al. The emergence of a novel coronavirus (SARS-CoV-2), their biology and therapeutic options. Journal of Clinical Microbiology 2020. DOI:10.1128/JCM.00187-20.

[24] Totura AL, Bavari S. Broad-spectrum coronavirus antiviral drug discovery. Expert Opinion in Drug Discovery 2019; 14: 397-412.

[25] Cvetkovic RS, Goa KL. Lopinavir/ritonavir: a review of its use in the management of HIV infection. Drugs 2003; 63(8): 769-802.

[26] Chan KS, Lai ST, Chu CM, et al. Treatment of severe acute respiratory syndrome with lopinavir/ritonavir: a multicentre retrospective matched cohort study. Hong Kong Med J. 2003; 9: 399406.

[27] Chu CM, Cheng VC, Hung IF, et al. Role of lopinavir/ritonavir in the treatment of SARS: initial virological and clinical findings. Thorax 2004; 59(3): 252-256.

[28] Chong YP, Song JY, Seo YB, et al. Antiviral treatment guidelines for Middle East respiratory syndrome. Infect Chemother 2015; 47: 212-222.

[29] Arabi YM, Asiri AY, Assiri AM, et al. Treatment of Middle East respiratory syndrome with a combination of lopinavir/ritonavir and interferon- $\beta 1 \mathrm{~b}$ (MIRACLE trial): statistical analysis plan for a recursive two-stage group sequential randomized controlled trial. Trials. 2020; 21(1): 8.

[30] Kempf DJ, Marsh KC, Kumar G, et al. Pharmacokinetic enhancement of inhibitors of the human immunodeficiency virus protease by coadministration with ritonavir. Antimicrob. Agents Chemother. 1997; 41(3): 654-660.

[31] Sham HL, Kempf DJ, Molla A, et al. ABT-378, a highly potent inhibitor of the human immunodeficiency virus protease. Antimicrob. Agents Chemother. 1998; 42(12): 3218-3224. 
[32] de Wilde AH, Jochmans D, Posthuma CC, et al. Screening of an FDA-approved compound library identifies four small-molecule inhibitors of Middle East respiratory syndrome coronavirus replication in cell culture. Antimicrob. Agents Chemother. 2014; 58(8): 4875-4884.

[33] Choy KT, Yin-Lam Wong A, et al. Remdesivir, lopinavir, emetine, and homoharringtonine inhibit SARS-CoV-2 replication in vitro. Antiviral Research 2020; 104786. DOI: 10.1016/j.antiviral.2020.104786.

[34] Cao B, Wang Y, Wen D, et al. A Trial of Lopinavir-Ritonavir in Adults Hospitalized with Severe Covid19. New England Journal of Medicine 2020. DOI: 10.1056/NEJMoa2001282.

[35] Yan D, Liu X-y, Zhu Y-n, et al. Factors associated with prolonged viral shedding and impact of Lopinavir/Ritonavir treatment in patients with SARS-CoV-2 infection. Medrexiv Preprint, 2020. doi: $10.1101 / 2020.03 .22 .20040832$.

[36] Dahlén SE. Treatment of asthma with antileukotrienes: first line or last resort therapy? European Journal of Pharmacology 2006; 533(1-3): 40-56.

[37] He J, Hu XP, Zeng Y, et al. Advanced research on acteoside for chemistry and bioactivities. Journal of Asian Natural Products Research 2011; 13(5): 449-464.

[38] Yang J, Guoa J, Yuan J. In vitro antioxidant properties of rutin. LWT 2008; 41: 1060-1066.

[39] Patel K, Patel DK. The Beneficial Role of Rutin, A Naturally Occurring Flavonoid in Health Promotion and Disease Prevention: A Systematic Review and Update. Bioactive Food as Dietary Interventions for Arthritis and Related Inflammatory Diseases, 2019; 457-479. DOI: 10.1016/b978-0-12813820-5.00026-x.

[40] Chen N, Zhou M, Dong X, et al. Epidemiological and clinical characteristics of 99 cases of 2019 novel coronavirus pneumonia in Wuhan, China: a descriptive study. Lancet 2020; 395: 507-513.

[41] Yang M. Cell pyroptosis, a potential pathogenic mechanism of 2019-nCoV infection. SSRN 2020. DOI: $10.2139 /$ ssrn.3527420.

[42] Guan WJ, Ni ZY, Hu Y, et al. Clinical characteristics of 2019 novel coronavirus infection in China. MedRxiv Preprint 2020. DOI: 10.1101/2020.02.06.20020974.

[43] Chen IY, Moriyama M, Chang MF, Ichinohe T. Severe acute respiratory syndrome coronavirus viroporin 3a activates the NLRP3 inflammasome. Front Microbiol 2019; 10: 50.

[44] Fu Y, Cheng Y, Wu Y. Understanding SARS-CoV-2-Mediated Inflammatory Responses: From Mechanisms to Potential Therapeutic Tools. Virologica Sinica 2020. DOI: 10.1007/s12250-020-00207-4.

[45] Ni L, Zhou L, Zhou M, Zhao J, Wang DW. 2020. Combination of western medicine and Chinese traditional patent medicine in treating a family case of COVID-19 in Wuhan. Front Med. 2020. DOI: 
10.1007/s11684-020-0757-x.

\section{Table}

Table 1: Table showing the list of compounds / drugs used in the present study, their physicochemical properties and docking scores. The docking scores were obtained following docking using Molegro Virtual Docker 6.0 software. 


\begin{tabular}{|c|c|c|c|c|c|}
\hline $\begin{array}{l}\text { Name of compound / } \\
\text { inhibitor }\end{array}$ & $\begin{array}{l}\text { PubChem } \\
\text { ID }\end{array}$ & $\begin{array}{l}\text { MolDock } \\
\text { Score }\end{array}$ & $\begin{array}{l}\text { Rerank } \\
\text { Score }\end{array}$ & HBond & Remarks \\
\hline Ritonavir & 392622 & -191.681 & -145.68 & -7.68331 & $\begin{array}{l}\text { Known } \\
\text { inhibitor }\end{array}$ \\
\hline Indinavir & 5362440 & -169.518 & -131.986 & -7.07843 & $\begin{array}{l}\text { Known } \\
\text { inhibitor }\end{array}$ \\
\hline Montelukast & 5281040 & -171.568 & -130.33 & -10.8343 & Wu et al. 2020 \\
\hline Acteoside & 5281800 & -142.815 & -126.769 & -16.9199 & Phytochemical \\
\hline Nelfinavir & 64143 & -156.375 & -123.755 & -13.4594 & $\begin{array}{l}\text { Known } \\
\text { inhibitor }\end{array}$ \\
\hline Rutin & 5280805 & -146.196 & -122.459 & -12.3004 & Phytochemical \\
\hline Candoxatril & 5362417 & -164.386 & -119.547 & -8.08428 & Wu et al. 2020 \\
\hline Tigecycline & 54686904 & -130.209 & -118.945 & -11.3303 & Wu et al. 2020 \\
\hline Lopinavir & 92727 & -172.448 & -117.421 & 0.06577 & $\begin{array}{l}\text { Known } \\
\text { inhibitor }\end{array}$ \\
\hline Almitrine & 33887 & -141.513 & -115.477 & -3.4736 & Wu et al. 2020 \\
\hline $14 b^{\star}$ & - & -150.217 & -112.525 & -6.76198 & $\begin{array}{l}\text { Ketoamide } \\
\text { inhibitor }\end{array}$ \\
\hline Curcumin & 969516 & -129.902 & -112.396 & -4.43329 & Phytochemical \\
\hline Rosmarinic acid & 5281792 & -131.984 & -111.052 & -15.3093 & Phytochemical \\
\hline Bis-demethoxycurcumin & 5315472 & -132.107 & -110.963 & -5 & Phytochemical \\
\hline Saquinavir & 441243 & -166.614 & -110.767 & -3.17374 & $\begin{array}{l}\text { Known } \\
\text { inhibitor }\end{array}$ \\
\hline Pleconaril & 1684 & -135.398 & -108.824 & -8.21897 & $\begin{array}{l}\text { Known } \\
\text { inhibitor }\end{array}$ \\
\hline Cilastatin & 6435415 & -130.666 & -108.738 & -4.60117 & Wu et al. 2020 \\
\hline Quercetin-3- $\beta$-D-glucoside & 5280804 & -119.668 & -108.271 & -15.4112 & $\begin{array}{l}\text { Known } \\
\text { inhibitor }\end{array}$ \\
\hline Amprenavir & 65016 & -142.83 & -108.185 & -4.77329 & $\begin{array}{l}\text { Known } \\
\text { inhibitor }\end{array}$ \\
\hline Demethoxycurcumin & 5469424 & -130.989 & -107.374 & -4.83556 & Phytochemical \\
\hline Cefpiramide & 636405 & -163.523 & -107.077 & -9.71581 & Wu et al. 2020 \\
\hline Pioglitazone & 4829 & -132.337 & -107.07 & -8.57175 & Wu et al. 2020 \\
\hline Withaferin A & 265237 & -125.824 & -104.903 & -5.64581 & Phytochemical \\
\hline
\end{tabular}




\begin{tabular}{|c|c|c|c|c|c|}
\hline Puerarin & 5281807 & -119.323 & -104.881 & -12.7102 & Phytochemical \\
\hline $11 r^{*}$ & - & -165.451 & -103.461 & -4.55018 & $\begin{array}{l}\text { Ketoamide } \\
\text { inhibitor }\end{array}$ \\
\hline Alfuzosin & 2092 & -124.293 & -101.327 & -10.9508 & Wu et al. 2020 \\
\hline Carvedilol & 2585 & -138.689 & -101.257 & -7.08229 & Wu et al. 2020 \\
\hline Isobavachalcone & 5281255 & -124.512 & -101.216 & -6.4969 & $\begin{array}{l}\text { Known } \\
\text { inhibitor }\end{array}$ \\
\hline Paeoniflorin & 442534 & -130.31 & -99.7539 & -13.5334 & Phytochemical \\
\hline Phenethicillin & 272833 & -127.122 & -98.6297 & -5.13691 & Wu et al. 2020 \\
\hline Carminic acid & 10255083 & -100.751 & -96.9069 & -18.7213 & Phytochemical \\
\hline Sesamin & 72307 & -130.68 & -96.4424 & 0 & Phytochemical \\
\hline Quercetin & 5280343 & -106.728 & -95.9808 & -13.4112 & Phytochemical \\
\hline Chrysotoxine & 5315860 & -111.147 & -95.5632 & -5.71678 & Phytochemical \\
\hline Famotidine & 5702160 & -106.463 & -92.5482 & -7.82187 & Wu et al. 2020 \\
\hline Catechin & 9064 & -108.479 & -92.4243 & -12.6705 & Phytochemical \\
\hline Helichrysetin & 6253344 & -110.409 & -92.2142 & -13.0345 & $\begin{array}{l}\text { Known } \\
\text { inhibitor }\end{array}$ \\
\hline Kaempferol & 5280863 & -102.499 & -91.2825 & -10.9606 & Phytochemical \\
\hline Sesaminol & 94672 & -134.694 & -91.2395 & -2.68177 & Phytochemical \\
\hline Resveratrol & 445154 & -108.239 & -90.5939 & -7.26707 & Phytochemical \\
\hline Dronabinol & 16078 & -108.491 & -89.155 & -4.94748 & Phytochemical \\
\hline Nordihydroguaiaretic acid & 4534 & -106.585 & -88.9944 & -10.6845 & Phytochemical \\
\hline Rosmanol & 13966122 & -99.2136 & -88.7562 & -8.59965 & Phytochemical \\
\hline Demeclocycline & 54680690 & -91.3397 & -88.658 & -4.20822 & Wu et al. 2020 \\
\hline EGCG & 65064 & -131.494 & -88.4334 & -13.1813 & Phytochemical \\
\hline Telmisartan & 65999 & -196.847 & -88.0605 & -3.37205 & Wu et al. 2020 \\
\hline Tenuigenin & 12442762 & -121.5 & -87.2238 & -3.51168 & Phytochemical \\
\hline Withanolide A & 11294368 & -104.876 & -85.7868 & -0.815134 & Phytochemical \\
\hline Herbacetin & 5280544 & -97.3802 & -85.702 & -15.6582 & $\begin{array}{l}\text { Known } \\
\text { inhibitor }\end{array}$ \\
\hline Nicardipine & 4474 & -145.672 & -81.5043 & -1.77899 & Wu et al. 2020 \\
\hline
\end{tabular}




\begin{tabular}{|c|c|c|c|c|c|}
\hline Conivaptan & 151171 & -145.915 & -79.269 & -0.776034 & Wu et al. 2020 \\
\hline Disulfiram & 3117 & -97.9229 & -79.2022 & 0 & $\begin{array}{l}\text { Known } \\
\text { inhibitor }\end{array}$ \\
\hline Ginkgolide A & 9909368 & -118.068 & -78.8825 & -7.90312 & Phytochemical \\
\hline Carnosol & 442009 & -94.8403 & -77.9083 & -7.08391 & Phytochemical \\
\hline Morin & 5281670 & -93.8023 & -77.1992 & -11.1263 & Phytochemical \\
\hline Flavin mononucleotide & 643976 & -118.384 & -77.0244 & -13.4506 & Wu et al. 2020 \\
\hline Estradiol valerate & 13791 & -110.47 & -75.9955 & -2.47672 & Wu et al. 2020 \\
\hline Epigallocatechin & 72277 & -99.5012 & -74.8905 & -12.0698 & Phytochemical \\
\hline Nepafenac & 151075 & -87.9547 & -73.6417 & -7.97907 & Wu et al. 2020 \\
\hline Mimosine & 3862 & -81.0206 & -69.8286 & -8.63722 & Wu et al. 2020 \\
\hline Withanone & 21679027 & -94.6249 & -69.416 & -9.39424 & Phytochemical \\
\hline L-theanine & 439378 & -79.1674 & -67.8436 & -7.45009 & Phytochemical \\
\hline Zingerone & 31211 & -81.7395 & -67.6862 & -2.54689 & Phytochemical \\
\hline Genistein & 5280961 & -90.1996 & -67.3383 & -9.76587 & Phytochemical \\
\hline Carnosic acid & 65126 & -83.2482 & -66.0006 & -8.34816 & Phytochemical \\
\hline Caffeic acid & 689043 & -77.1921 & -63.2921 & -5.05571 & $\begin{array}{l}\text { Known } \\
\text { inhibitor }\end{array}$ \\
\hline Thymoquinone & 10281 & -71.1736 & -61.7502 & -4.5178 & Phytochemical \\
\hline Isatin & 7054 & -71.2818 & -61.5046 & -1.78669 & $\begin{array}{l}\text { Known } \\
\text { inhibitor }\end{array}$ \\
\hline Favipiravir & 492405 & -66.9781 & -60.5145 & -7.16454 & $\begin{array}{l}\text { Known } \\
\text { inhibitor }\end{array}$ \\
\hline Ellagic acid & 5281855 & -78.964 & -59.3876 & -6.94904 & Phytochemical \\
\hline Gallic acid & 370 & -67.2234 & -58.4605 & -12.0867 & Phytochemical \\
\hline p-Coumaric acid & 637542 & -74.1294 & -58.413 & -3.06399 & Phytochemical \\
\hline Sesamol & 68289 & -66.0625 & -51.9265 & -4.40782 & Phytochemical \\
\hline Limonene & 22311 & -61.1149 & -50.8082 & 0 & Phytochemical \\
\hline Diisopropylfluorophosphate & 5936 & -61.8131 & -49.1607 & -0.823786 & $\begin{array}{l}\text { Known } \\
\text { inhibitor }\end{array}$ \\
\hline Doxycycline & 54671203 & -97.647 & -47.021 & -6.0814 & Wu et al. 2020 \\
\hline Oxytetracycline & 54675779 & -96.0528 & -42.9165 & -7.84098 & Wu et al. 2020 \\
\hline
\end{tabular}




\begin{tabular}{|llllll|}
\hline Chlorhexidine & 9552079 & -124.171 & -36.8801 & -11.4681 & Wu et al. 2020 \\
\hline Limecycline & 54675776 & -94.2957 & -33.9643 & -5.55622 & Wu et al. 2020 \\
\hline Lutein & 5281243 & -119.461 & 1.62241 & 0 & Wu et al. 2020 \\
\hline Garcinol & 5281560 & -131.293 & 5.40054 & -13.0189 & Phytochemical \\
\hline Lycopene & 446925 & 23.4536 & 160.484 & 0 & Phytochemical \\
\hline
\end{tabular}

*13r and 14b are a-ketoamides which have been suggested by Wu et al. (2020) as inhibitors of the main protease of SARS-CoV-2.

Figures 

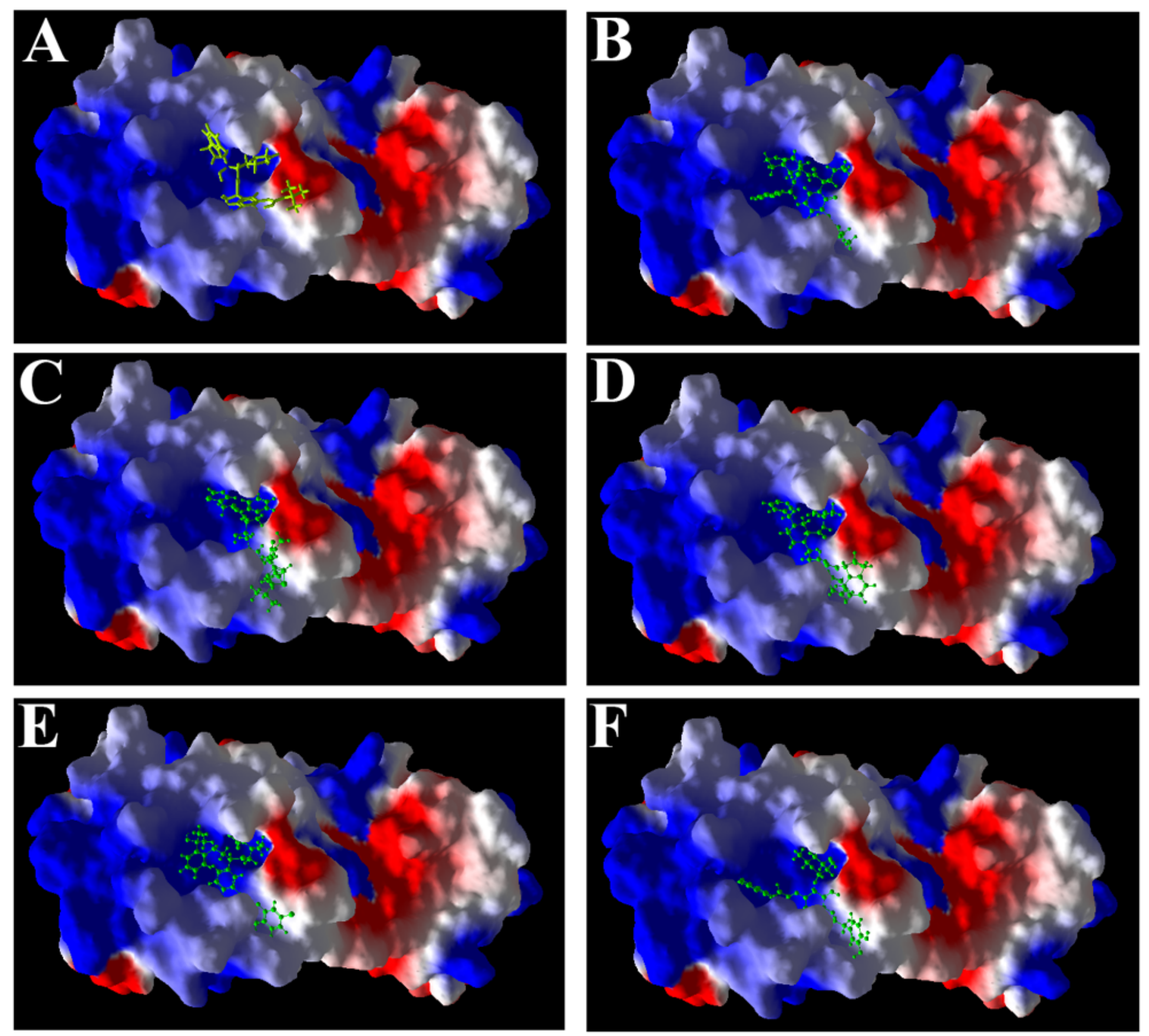

\section{Figure 1}

Docking poses of different compounds under investigation at the active site of 3CL protease (main protease) of SARS-CoV-2. (A) Pose of original co-crystallized ketoamide, and Docked poses of: (B) Cocrystallized ketoamide, (C) Ritonavir, (D) Indinavir, (E) Montelukast and (F): Acteoside. All these ligands bind to the same active binding site of the co-crystallized ketoamide. The poses were developed following docking using Molegro Virtual Docker 6.0 software. The pose of the co-crystallized compound (ketoamide) and the pose of the same compound when docked are same, which validates the docking study. 